\title{
Aspects Concerning the Processing of Observations in Support Networks Related to Hydropower Objectives
}

\author{
Mircea ORTELECAN ${ }^{11}$, Ioana POP ${ }^{1)}$, Tudor SĂLĂGEAN ${ }^{\left.1^{*}\right)}$, Paul SESTRAŞ ${ }^{1)}$ and Nicolae POP ${ }^{1)}$ \\ ${ }^{1)}$ Faculty of Horticulture, University of Agricultural Science and Veterinary Medicine, \\ Calea Mănăştur 3-5, 400372, Cluj-Napoca, Romania. \\ ${ }^{*}$ Corresponding author, e-mail: tudor.salagean@usamvcluj.ro
}

Bulletin UASVM Horticulture 71(2) / 2014

Print ISSN 1843-5254, Electronic ISSN 1843-5394

DOI:10.15835/buasvmcn-hort:10660

\begin{abstract}
Models for processing geodetic observations made in support networks related to hydropower objectives are the ones used in general geodetic networks. For geodetic observations processing, based on the type of measurements made, are used mathematical models corresponding to indirect and conditioned measurements of same precision or different precision. The purpose of this paper is to highlight some aspects regarding the importance of using mathematical models for processing observations in support networks related to hydropower objectives. The case study concerning the geodetic observations processing of support networks related to hydropower objectives was made on the arrangements from the superior part of Someș Cald river in Romania. The geodetic observations carried out in the support network were made using the total station Leica TM 30 and for processing were used the mathematical models which were previously mentioned. The accuracy of determining the coordinates of the support network is conditioned by the measurement accuracy and by the mathematical model which was used in processing. After determining the stability of the network points we could conclude that the parameter values obtained by the method of conditional measurements are substantially equal to those determined from indirect measurements. The displacement values obtained through the matrix and Gauss-Doolittle method are identical, which shows the correctness of calculations. Also the standard deviation of the most probable values is below millimeter. The biggest displacements are registered at point PIV, for which it should not be used for determining the displacement of the tracking marks placed on the dam.
\end{abstract}

Keywords: geodetic networks, heterogeneous measurements, processing models

\section{INTRODUCTION}

The facilities of water conservancy and hydropower in each country are developing quickly and the accompanying problems on the dam security were stood out increasingly. In China, the problems were extremely severe, for instance, according to the surveying results of MWR (Ministry of Water Resources) in China, in 2008 , the risk rate of the dams was nearly $36 \%$. For most of the problems, the risks were focused on the middle and small storage reservoirs and monitoring of dam security was therefore paid a lot of attention, not only in China, but also in many European countries (Wang and Yan, 2013).

Support networks, related to pursuing the hydropower objectives are presented under the form of local micro-triangulation networks, micro-trilateration or triangulation-trilateration, characterized by high accuracy required for determining the position of the target marks which are placed on the objective (Ghiţău, 1983; Ortelecan, 2006).

The purpose of this paper is to highlight some aspects regarding the importance of using mathematical models in processing observations in support networks related to hydropower objectives. Theoretical aspects aime to determine the stability of the local network for monitoring the hydropower construction from a measurement epoch to another, based on indirectand conditioned measurements.

Tracking the support network stability was based on the statistical test of limit differences 


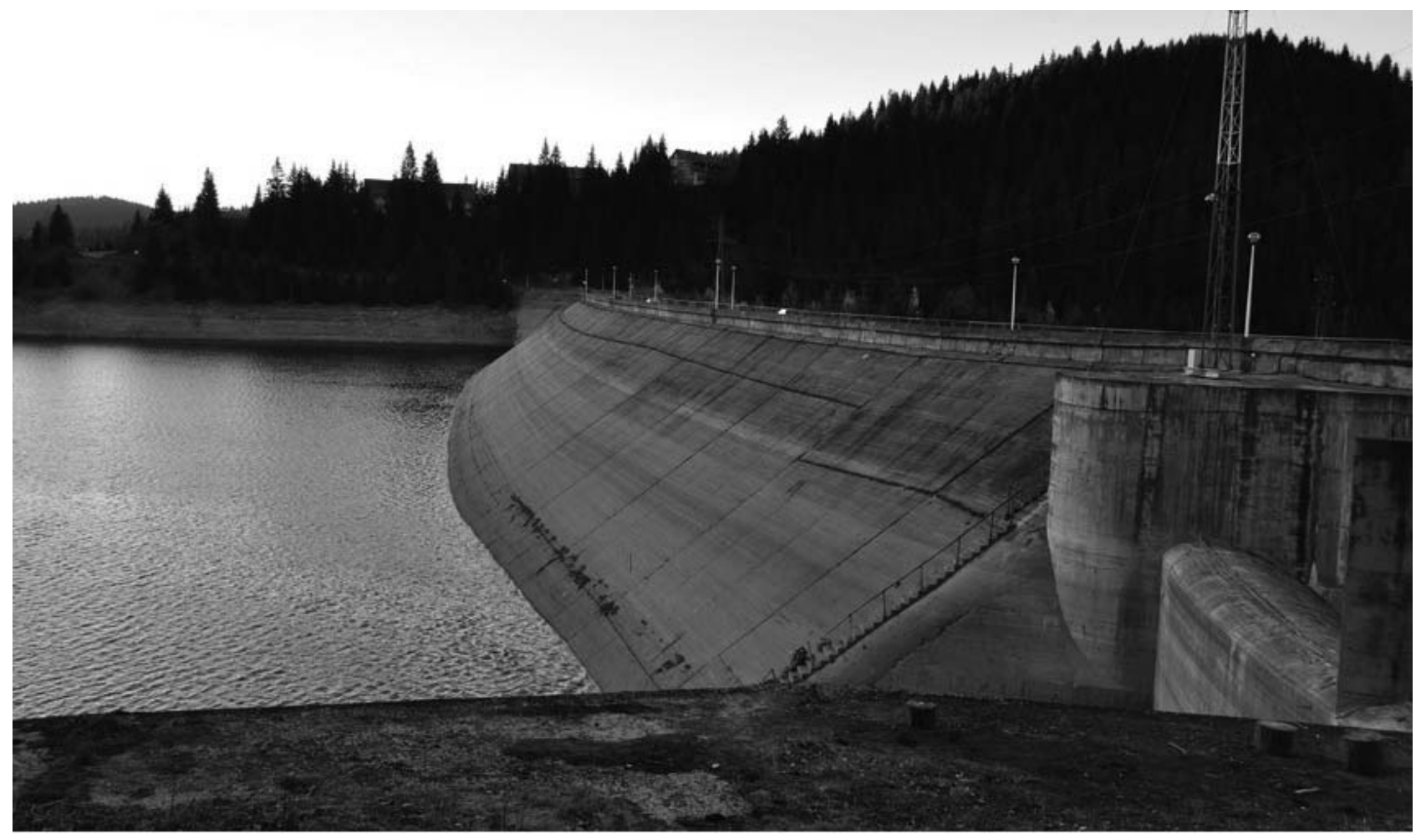

Fig. 1. Beliş-Fântânele dam

(DL), calculated from theoretical values of Student Ficher (SF 5\%) and the Helmert deviation of the mean square errors of the points.

The methods commonly used in deformation monitoring include geodetic method, special measurement means (containing various alignment measurement, inclinometer measurement, liquid static leveling system and strain gauge measurement), photogrammetry methods, GPS measurement, 3D scanning etc. (Li and Wang, 2011).

Deformation measurements have an important status among various engineering surveying. The self-weight of a dam and the reservoir water pressure are primarily responsible for the increase of stresses within the dam body, which in time result in horizontal and vertical displacements, mostly of a permanent character (Kalkan et al., 2010).

The support network pilasters, from which are made the azimuth, zenith and distances observations, are built of reinforced concrete, solidly embedded in the bedrock and have on top a special plate for forced centering of the geodetic instruments.
In processing the geodetic observations, based on the type of measurements made, are used mathematical models appropriate for indirect measurements and conditioned measurements of same precision or of different precision (Fotescu and Savulescu, 1988; Dima et al., 1999). The support network coordinates are usually given in a local system and sometimes are framed in the national system (Moldoveanu, 2002). The accuracy of determining the coordinates of the support network is conditioned by the measurement accuracy and by the mathematical model which was used in processing.

\section{MATERIALS AND METHODS}

The case study regarding the processing of geodetic observations in support networks related to hydropower objectives was achieved on a micro-local micro-triangulation network located downstream Beliş -Fântânele dam (fig. 1) which is situated in the upstream of the Someş Cald river, Cluj county.

The network is formed of five pilasters (fig.2), whose coordinates at the base measurement are presented in table 2 . 


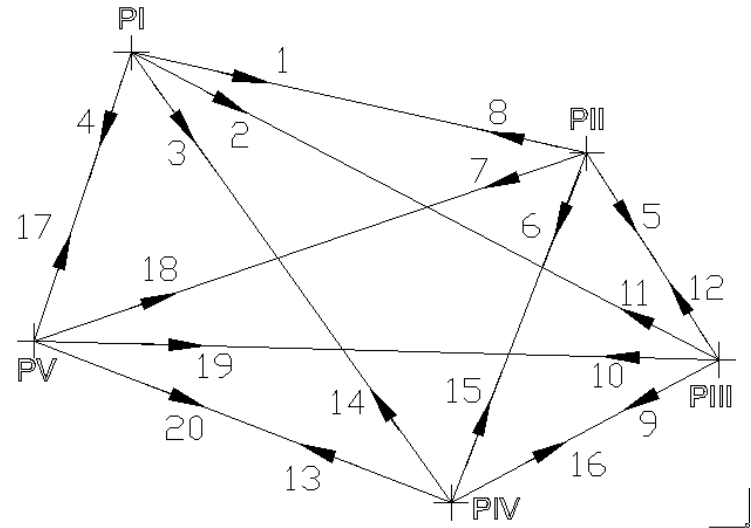

Fig. 2. Support network with the measured azimuth directions

Tab. 1. - The network coordinates at the base measurement

\begin{tabular}{cccc}
\hline Point & X & Y & Point type \\
\hline PI & 796.3631 & 507.3803 & Fix \\
\hline PII & 753.7017 & 699.8219 & Fix \\
\hline PIII & 666.3195 & 755.4734 & Temporary \\
\hline PIV & 605.7958 & 642.5016 & Temporary \\
\hline PV & 674.3654 & 466.3561 & Temporary \\
\hline
\end{tabular}

The axis of the local coordinate system are oriented as follows:

- X axis is oriented on the upstream - downstream direction, with growth sense to downstream.

- Y axis is oriented on the left bank-right bank direction, with growth sense of the coordinates to the right bank.

The geodetic observations made in the support networks were performed using Leica TM 30 total station through reiterated complete series method. The azimuthal directions values are presented in table 2 .

$$
\begin{aligned}
& a_{2} d x_{P_{I I I}}+b_{2} d y_{P_{I I I}}+l_{2}=v_{2} ; \quad p=1 \\
& a_{3} d x_{P_{I V}}+b_{3} d y_{P_{I V}}+l_{3}=v_{3} ; \quad p=1 \\
& a_{5} d x_{P_{V}}+b_{5} d y_{P_{V}}+l_{5}=v_{5} ; \quad p=1 \\
& \frac{a_{2}}{\sqrt{4}} d x_{P_{I I I}}+\frac{b_{2}}{\sqrt{4}} d y_{P_{I I I}}+\frac{a_{3}}{\sqrt{4}} d x_{P_{I V}}+\frac{b_{3}}{\sqrt{4}} d y_{P_{I V}}+\frac{a_{4}}{\sqrt{4}} d x_{P_{V}}+\frac{b_{4}}{\sqrt{4}} d y_{P_{V}}=v^{\prime} ; \quad p=-1 \\
& -a_{17} d x_{P_{V}}-b_{17} d y_{P_{V}}+l_{17}=v_{17} ; \quad p=1 \\
& -a_{18} d x_{P_{V}}-b_{18} d y_{P_{V}}+l_{18}=v_{18} ; \quad p=1 \\
& -a_{19} d x_{P_{V}}-b_{19} d y_{P_{V}}+a_{19} d x_{P_{I I I}}+b_{19} d y_{P_{I I I}}+l_{19}=v_{19} ; \quad p=1 \\
& -a_{20} d x_{P_{V}}-b_{20} d y_{P_{V}}+a_{20} d x_{P_{I V}}+b_{20} d y_{P_{I V}}+l_{20}=v_{20} ; \quad p=1 \\
& \frac{[a]}{\sqrt{4}} d x_{P_{V}}+\frac{[b]}{\sqrt{4}} d y_{P_{V}}+\frac{a_{19}}{\sqrt{4}} d x_{P_{I I I}}+\frac{b_{19}}{\sqrt{4}} d y_{P_{I I I}}+\frac{a_{20}}{\sqrt{4}} d x_{P_{I V}}+\frac{b_{20}}{\sqrt{4}} d y_{P_{I V}}=v^{\prime} ; \quad p=-1
\end{aligned}
$$


Where:

$a_{i}=-\rho^{c} \frac{\sin \theta_{i}}{D_{j}} ; \quad b_{i}=-\rho^{c} \frac{\cos \theta_{i}}{D_{j}}$

The equations system in the matrix form is presented in equation (2):

$$
\text { X }+l=V
$$

where :

$\mathrm{X}$ - is the vector of unknowns;

A - matrix of direction coefficients;

$l-$ vector of free terms.

Solution to determine the unknown parameters is obtained by applying equation (3).

$$
\mathrm{X}=-\left(\mathrm{A}^{\mathrm{T}} \mathrm{PA}\right)^{4} \mathrm{~A}^{\mathrm{T}} \mathrm{P} l=-N^{-1} l *
$$

where:

$\mathrm{P}$ - weightings matrix

According to Ghiţău (1983), the vector of unknowns (3) takes the form:

$$
\mathrm{X}=N^{-1} l^{*}
$$

where:

$\mathrm{N}^{-1}=\left(\mathrm{A}^{\mathrm{T}} \mathrm{PA}\right)^{-1}$

$l^{*}=\mathrm{A}^{\mathrm{T}} \mathrm{Pl}$

Stochastic model is given by the diagonal matrix of weightings $P_{(19,19)}$.

The compensated values of the parameters $X$ and the measurements $M$ result from:

$$
\begin{aligned}
& (X)=X^{0}+X \\
& M=M^{0}+v
\end{aligned}
$$

The standard deviation of unit weightings is calculated by the formula:

$s_{0}= \pm \sqrt{\frac{v^{T} \boldsymbol{P}}{n-k}}$

where:

$\mathrm{n}$ - equations number;

$\mathrm{k}$ - number of unknowns from the initial system.

The standard deviation of the probable values are calculated with the relations: $s_{x}= \pm s_{0} \sqrt{Q_{x}}$
$s_{y}= \pm s_{0} \sqrt{Q_{y}}$

where:

$Q_{x x^{\prime}}, Q_{y y}-$ weightings coefficients.

Because standard deviations changes its value in the case of changing the coordinate system, the local accuracy is expressed by error ellipse, which does not depend on the axis system under which the compensation is done, only by the configuration of the geodetic network and by measurement accuracy.

The parameters of the errors ellipse:

- the big semi-axis "a", respectively the small semiaxis " $\mathrm{b}$ ", is calculated with the relations:

$a=s_{0} \sqrt{\lambda}_{1}$

$b=s_{0} \sqrt{\lambda}_{2}$

$\lambda_{1}=\frac{Q_{x}+Q_{y}}{2}+\frac{1}{2} \sqrt{\left(Q_{x}-Q_{y}\right)^{2}+4 Q_{y}^{2}}$

$\lambda_{2}=\frac{Q_{x}+Q_{y}}{2}-\frac{1}{2} \sqrt{\left(Q_{x}-Q_{y}\right)^{2}+4 Q_{x}^{2}}$

- the big axis orientation of the ellipse in relation to the axis " $x$ " of the coordinate system is determined by the relation:

$\theta=\frac{1}{2} \operatorname{arctg} \frac{2 Q_{\Varangle}}{Q_{x}-Q_{y}}$

After compensation, separately on measurement epochs in the partial minimum condition, for the points which make up the common reference data, will be calculated displacements between two measurement periods, with relations:

$$
\Delta D_{\mathrm{P}}=\sqrt{\left(X_{i+1}-X_{i}\right)^{2}+\left(Y_{i+1}-Y_{i}\right)^{2}}
$$

It is considered that the points are stable between two epochs of measurements in the case you check the inequality:

$\left|\Delta D_{P}\right|<t_{k}\left|S_{P}\right|$

Where $S_{p}$ is the Helmert total average error of the point $P$, and $t_{k}=t(S, f)$ is the statistic calculated 


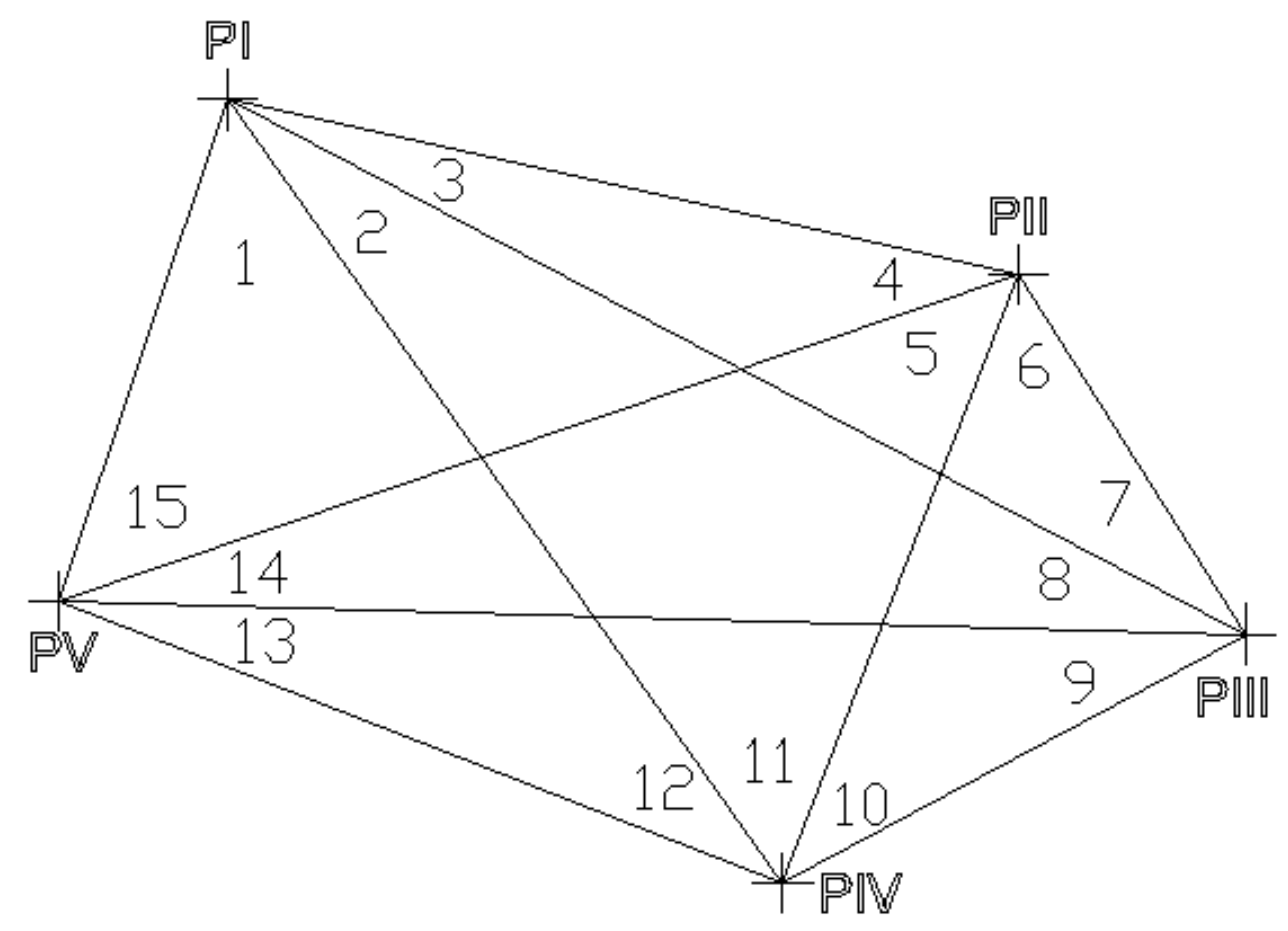

Fig. 3. The micro-triangulation network compensated on angles

for point $\mathrm{P}$, where $\mathrm{S}$ is the safety threshold being operated, and $f$ is the number of additional measurements available in the geodetic network in the two sets of observations.

When using conditional measurements for solving support networks, the compensation of measured elements will be done according to the angles obtained by the measured directions difference (fig. 3).

Establishing the number of condition equations for the network taken into study resulted 9 equations of geometric conditions, from which 6 conditions of figure and 3 geometric conditions of pole, established for the quadrilaterals PI, PII, PIV, PV - PI, PII, PIII, PIV - PII , PIII, PIV, PV. Corresponding to the nine geometric conditions will determine the appropriate correction equations corresponding to the conditioned measurements of same precision. The system of correction equations is given by relations (11):

$$
\begin{aligned}
& v_{1}+v_{2}+v_{3}+v_{15}+w_{1}=0 \\
& v_{2}+v_{3}+v_{4}+v_{5}+v_{11}+w_{2}=0 \\
& v_{5}+v_{11}+v_{12}+v_{13}+v_{14}+w_{3}=0 \\
& v_{6}+v_{7}+v_{8}+v_{9}+v_{10}+w_{4}=0 \\
& v_{3}+v_{4}+v_{5}+v_{6}+v_{7}+w_{5}=0 \\
& v_{9}+v_{10}+v_{12}+v_{13}+w_{6}=0 \\
& d_{1} v_{1}-d_{2,3}\left(v_{2}+v_{3}\right)+d_{4} v_{4}-d_{5} v_{5}+d_{11} v_{11}-d_{12} v_{12}+d_{13,14}\left(v_{13}+v_{14}\right)-d_{15} v_{15}+w_{7}=0 \\
& -d_{2} v_{2}+d_{3} v_{3}-d_{4,5}\left(v_{4}+v_{5}\right)+d_{6} v_{6}-d_{7} v_{7}+d_{8,9}\left(v_{8}+v_{9}\right)-d_{10} v_{10}+d_{11} v_{11}+w_{8}=0 \\
& d_{5} v_{5}-d_{6} v_{6}+d_{7,8}\left(v_{7}+v_{8}\right)-d_{9} v_{9}+d_{10} v_{10}-d_{11,12}\left(v_{11}+v_{12}\right)+d_{13} v_{13}-d_{14} v_{14}+w_{9}=0
\end{aligned}
$$


Written in matrix form, the system is presented in the form:

$$
\begin{array}{r}
B^{T} V=W \\
\text { unde: }
\end{array}
$$

$\mathrm{B}^{\mathrm{T}}$ - the transpose matrix of coefficients;

$\mathrm{V}$ - correction vector;

$\mathrm{W}$ - un-closures on the geometric conditions.

Correlates matrix is determined by the relation:

$$
k=\left(B^{T} B\right)^{-1} W
$$

Correction vector is calculated with the relation:

$$
V=B\left(B^{T} B\right)^{-1} W
$$

Average error of observations (standard deviation) is given by:

$$
S_{0}= \pm \sqrt{\frac{v^{T} v}{r}}
$$

The working methods used in the case study are consecrated in the specialty literature and were used in many $\mathrm{PhD}$ thesis and papers regarding dam monitoring.

Unlike other works regarding the monitoring of Beliş-Fântânele dam, this paper introduces the use of statistical assumptions in determining the stability of support network points associated with this dam.

\section{RESULTS AND DISCUSSIONS}

After processing the instrumental observations of indirect measurements carried out by the matrix method and by the Gauss Doolittle method, were obtained the displacement parameters on the coordinates axis and the linear movement of each point (Table 3) determined in the current epoch compared to the basis epoch.

The inverse matrix from relation (3), shown below, is the matrix of variance - covariance of the stochastic model, on its diagonal there are the weighting coefficients of the parameters of unknowns.

Tab. 3. Values of the displacement parameters

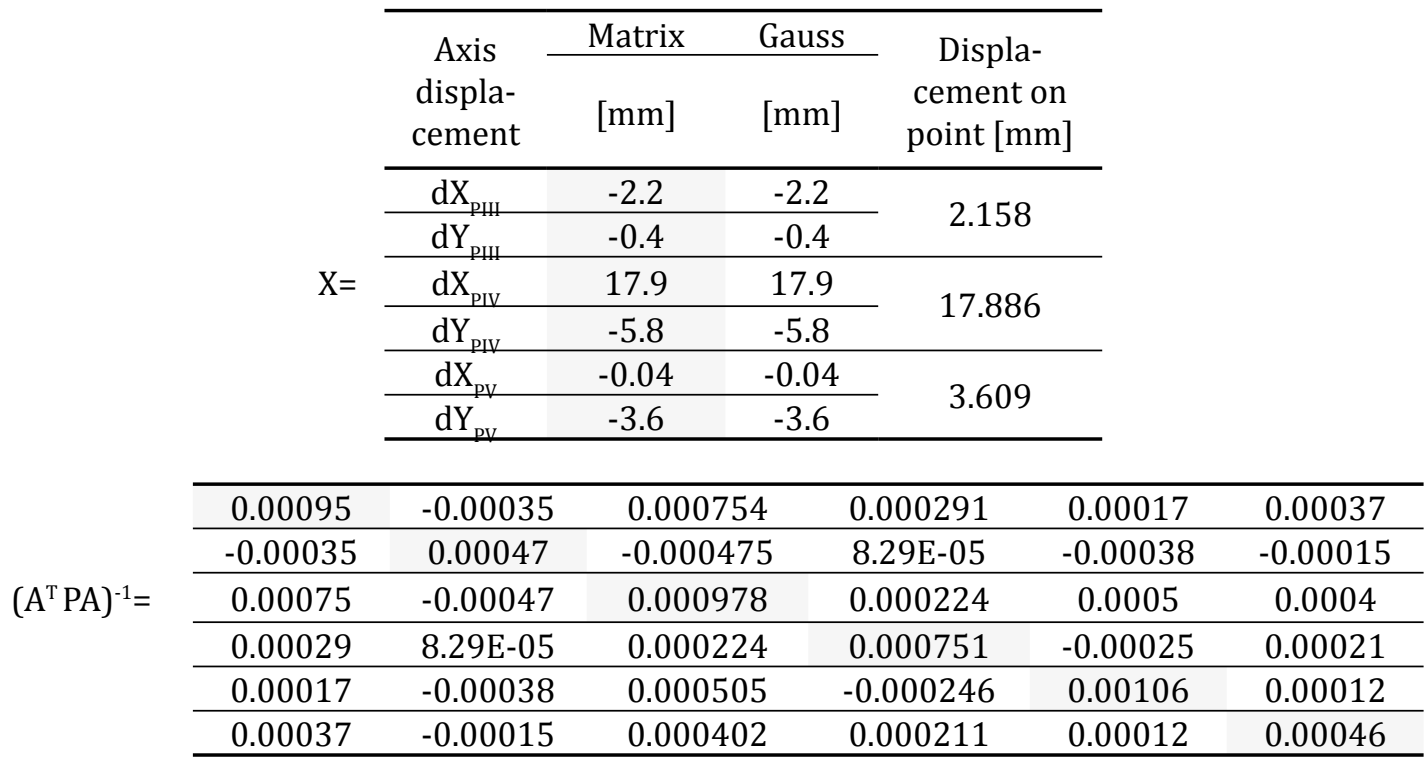

Tab. 4. Precision indices of the displacement parameters

\begin{tabular}{ccccccc}
\hline Point & $\mathrm{S}_{\mathrm{X}}[\mathrm{mm}]$ & $\mathrm{S}_{\mathrm{Y}}[\mathrm{mm}]$ & Helmert & $\mathrm{a}[\mathrm{mm}]$ & $\mathrm{b}[\mathrm{mm}]$ & $\mathrm{q}$ \\
\hline PIII & 0.99 & 0.69 & 1.21 & 1.08 & 0.54 & 380.1065 \\
\hline PIV & 1.00 & 0.88 & 1.33 & 1.07 & 0.79 & 24.7295 \\
\hline PV & 1.04 & 0.68 & 1.25 & 1.05 & 0.67 & 6.2691 \\
\hline
\end{tabular}


In table 4 are presented the standard deviations of the displacement parameters on two axes, the total linear deviation of the network points and the parameters of the error ellipse.

Checking values in table 4 , in conjunction with relation (10), we find that the inequality is not satisfied for point PIV, which shows that the point noted suffered a significant displacement in the current tranche compared to tranche zero (table 5). Incidentally this was expected given that this is located in one of the downstream parament of Beliş-Fântânele dam. Therefore that point will not be used to determine the displacements of the tracking marks because it would introduce errors in positioning the tracking marks.

Tab. 5. Verifying the points stability

\begin{tabular}{ccc}
\hline Point & $\begin{array}{c}\Delta \mathrm{D} \\
{[\mathrm{mm}]}\end{array}$ & $\mathrm{t}_{\mathrm{k}} \mathrm{S}_{\mathrm{H}}[\mathrm{mm}]$ \\
\hline $\mathrm{P}_{\mathrm{III}}$ & 2.158 & 3.0149 \\
\hline $\mathrm{P}_{\mathrm{IV}}$ & 17.886 & 3.327 \\
\hline $\mathrm{P}_{\mathrm{V}}$ & 3.609 & 3.1143 \\
\hline
\end{tabular}

In the case of using the conditioned measurements for solving the support networks, first are determined the corrections of the measured elements and after that using the compensated elements are calculated the orientations, the sides and the coordinates of the network points.

For determining the stability of the network points, is made the difference between the calculated coordinates at the current epoch compared to the base epoch. The calculated values are presented in table 6 . It is found that the parameter values obtained by the method of conditional measurements are substantially equal to those determined from indirect measurements.
Processing of geodetic observations in the support network was achieved by trilateration method, but the values obtained for the displacement of points were centimeters, which led to their exclusion. It therefore raises the problem of distance measurement accuracy achieved in network support at their disposal. Given this drawback, it has not been used the triangulation-trilateration method for solving the network.

From table 3 it is noted that the displacement values obtained through the matrix and GaussDoolittle method are identical, which shows the correctness of calculations.

Regarding the precision indices in table 4, it is observed that the standard deviation of the most probable values is below millimeter.

Comparing the linear displacements of the support network points from tables 3 and 6 it is noted that they have similar values, although they were obtained by different methods.

Analyzing the results obtained in table 6 we can observe that the biggest displacements are registered at point PIV, for which it should not be used for determining the displacement of the tracking marks placed on the dam.

\section{CONCLUSION}

The accuracy of determining the support network coordinates is conditioned by the measurement accuracy and by processing the mathematical model. Indirect measurement method used in the case repeated measurements of local micro-triangulation network offers the possibility of setting direct displacement parameters from the basic stage to the current stage or between two different measuring epochs. The method also allow the establishment of precision indicators (standard deviation of unit

Tab. 6. Point displacements

\begin{tabular}{cccccccc}
\hline \multirow{2}{*}{ Point } & \multicolumn{2}{c}{ Zero tranche } & \multicolumn{2}{c}{ Current tranche } & \multicolumn{3}{c}{ Deisplacements } \\
\cline { 2 - 7 } & $\mathrm{X}[\mathrm{m}]$ & $\mathrm{Y}[\mathrm{m}]$ & $\mathrm{X}[\mathrm{m}]$ & $\mathrm{Y}[\mathrm{m}]$ & $\mathrm{d}_{\mathrm{x}}[\mathrm{mm}]$ & $\mathrm{d}_{\mathrm{Y}}[\mathrm{mm}]$ & $\Delta \mathrm{D}[\mathrm{mm}]$ \\
\hline PI & 796.3631 & 507.3803 & 796.3631 & 507.3803 & 0.0 & 0.0 & 0.0 \\
\hline PII & 753.7017 & 699.8219 & 753.7017 & 699.8219 & 0.0 & 0.0 & 0.0 \\
\hline PIII & 666.3195 & 755.4734 & 666.31717 & 755.4733 & -2.3 & -0.1 & 2.3 \\
\hline PIV & 605.7958 & 642.5016 & 605.8135 & 642.4965 & 17.7 & -5.1 & 18.4 \\
\hline PV & 674.3654 & 466.3561 & 674.36461 & 466.3519 & -0.8 & -4.2 & 4.2 \\
\hline
\end{tabular}


weighting, standard deviation of probable values , Helmert error, parameters of the error ellipse) for positioning the tracking network points and the target marks placed on the dam. Solving the support networks through indirect measurement method lends itself well to a linear programming computer compared to conditional measurement method.

\section{REFERENCES}

1. Dima N, Herbei 0 and Vereș J (1999). The Theory of Errors and Method of Least Squares, Universitas Publishing House, Petroșani.

2. Fotescu N and Savulescu C (1988). Practical Works Guide for Errors Theory, Bucharest Construction Institute.
3. Ghițău D (1983). Geodesy and Geodetic Gravimetry. Didactic and Pedagogic Puplishing House, Bucharest.

4. Kalkan Y, Alkan R and Bilgi S (2010). Deformation Monitoring Studies at Ataturk Dam. Proceedings of the XXIV FIG Congress "Facing the Challenges - Building the Capacity", 11-16 April 2010, Sydney, Australia, ISBN 97887-90907-87-7: 10-24.

5. Li W and Wang C (2011). GPS in the Tailings Dam Deformation Monitoring. Procedia Engineering, 26: 16481657.

6. Moldoveanu C (2002). Geodesy. Matrix Rom Publishing House, Bucharest.

7. Ortelecan M (2006). Geodesy. AcademicPres Publishing House, Cluj-Napoca.

8. Wang X and Yan YM (2013). Research Status Summary on Dam Security Monitoring. Applied Mechanics and Materials, vol.405-408: 2473-2476. 